DOI:10.33099/2311-7249/2019-34-1-69-74

УДК: $358.4(004,42)$

Свгеній Олександрович Гришманов ${ }^{1}$

Ірина Вікторівна Захарченко (кандидат технічних наук) ${ }^{2}$

Ірина Вікторівна Новікова ${ }^{3}$

${ }^{1}$ Льотна академія Національного авіаційного університету, Кропивницький, Украӥна

${ }^{2}$ Харківський національний університет Повітряних Сил імені Івана Кожседуба, Харків, Україна

${ }^{3}$ Національний університет оборони Украӥни імені Івана Черняховського, Київ, Украӥна

\title{
МЕТОД ПРОГНОЗУВАННЯ НЕСПРИЯТЛИВИХ АВІАЦІЙНИХ ПОДІЙ ПІД ЧАС ПОЛЬОТУ НА ОСНОВІ ГІБРИДНИХ НЕЙРОННИХ MEPEЖ
}

В роботі представлено структуру методу прогнозування несприятливих авіаџійних подій під час польоту на основі згорткових нейронних мереж (CNN) та рекурентних нейронних мереж (RNN) на базі модулів LSTM. Безпосередньо під прогнозуванням в роботі мається на увазі вирішення задачі аналізу текстових повідомлень, щуо представлені у вигляді структурованого та неструктурованого тексту та формуються на основі даних, отриманих від різних джерел інформачії в прочесі управління повітряним рухом. Детально розглянуто прочедуру визначення гіперпараметрів та процедуру навчання гібридноі нейромережевої моделі для прогнозування несприятливих авіаційних подій в польоті з використанням CNN ma LSTM.

Ключові слова: безпека польотів, прогнозування, згорткова нейронна мережа, рекурентна нейронна мережа, модуль LSTM, функція активації, тензор.

\section{Вступ}

Постановка проблеми. Одним із важливих моментів забезпечення обороноздатності держави $\epsilon$ підвищення рівня безпеки польотів. Так, аналіз звітів [1-2], щодо стану безпеки польотів цивільної авіації за 2016-2018 роки не показав тенденції зменшення кількості авіаційних подій.

Перспективним напрямком вирішення даної проблеми $\epsilon$ розробка та впровадження автоматизованих систем управління авіаційними технічними засобами по різним показникам якості функціонування, у тому числі й безпекою польотів, які забезпечать можливість здійснювати прогнозування 3 метою прийняття своєчасних рішень по попередженню авіаційних подій. Основою таких систем $є$ математичне та програмне забезпечення.

Одним із варіантів при розробці методів прогнозування авіаційних подій $є$ застосування ймовірнісних методів аналізу небезпеки. Однак крім традиційних методів, вирішення вказаної задачі можливе здійснювати за допомогою нейронних мереж, які дозволяють забезпечувати більшу ефективність та якість аналізу за рахунок застосування в них алгоритмів глибокого навчання.

Аналіз останніх досліджень. В роботах $[3,4]$ запропоновано методи прогнозування та попередження авіаційних подій з використанням ймовірнісного аналізу та побудови дерева подій на основі інформації, яка отримується від різних джерел інформації і свідчить про фактори небезпеки. Однак питання наявності інформації у вигляді структурованих та неструктурованих даних у рамках запропонованих методів не достатньо розглянуті i потребують подальшого дослідження.

Мета статті. Розробка методу прогнозування несприятливих авіаційних подій під час польоту на основі використання глибоких нейронних мереж, а саме згорткових та рекурентних нейронних мереж.

\section{Виклад основного матеріалу}

\section{дослідження}

Під процесом прогнозування несприятливих авіаційних подій в роботі будемо мати на увазі вирішення задачі аналізу текстових повідомлень, які формуються на основі даних, отриманих в процесі управління повітряним рухом від різних джерел інформації. Аналіз текстових повідомлень полягає у виділенні ключових слів 3 наступним визначенням ймовірності виникнення авіаційної події деякого класу. При розробці методу прогнозування несприятливих авіаційних подій під час польоту у якості базового математичного апарату будемо використовувати рекурентні нейронні мережі (Recurrent Neural Networks

RNN) на базі модулів довгої короткострокової пам'яті (Long short-term memory $\square$ LSTM) та згорткові нейронні мережі (Convolutional neural network $\square$ CNN).

Аналіз можливостей даних мереж [5-6] показав, что RNN на базі модулів LSTM ефективні перш за все при аналізі структурованого тексту, під яким у даному випадку мається на увазі звіт про результати розслідування авіаційних подій. В свою чергу CNN ефективні у випадку неструктурованого тексту, у якості якого 
розглядаються текстові повідомлення стосовно ситуації, що складається під час польоту згідно даних зовнішніх джерел інформації.

Узагальнена структура методу прогнозування несприятливих авіаційних подій під час польоту на основі гібридної нейромережевої моделі 3 використанням згорткових та рекурентних нейронних мереж наведена на рисунку 1.
Метод прогнозування складається 3 наступних основних процедур:

1) процедури визначення базової архітектури нейромережевої моделі прогнозування несприятливих авіаційних подій в польоті.

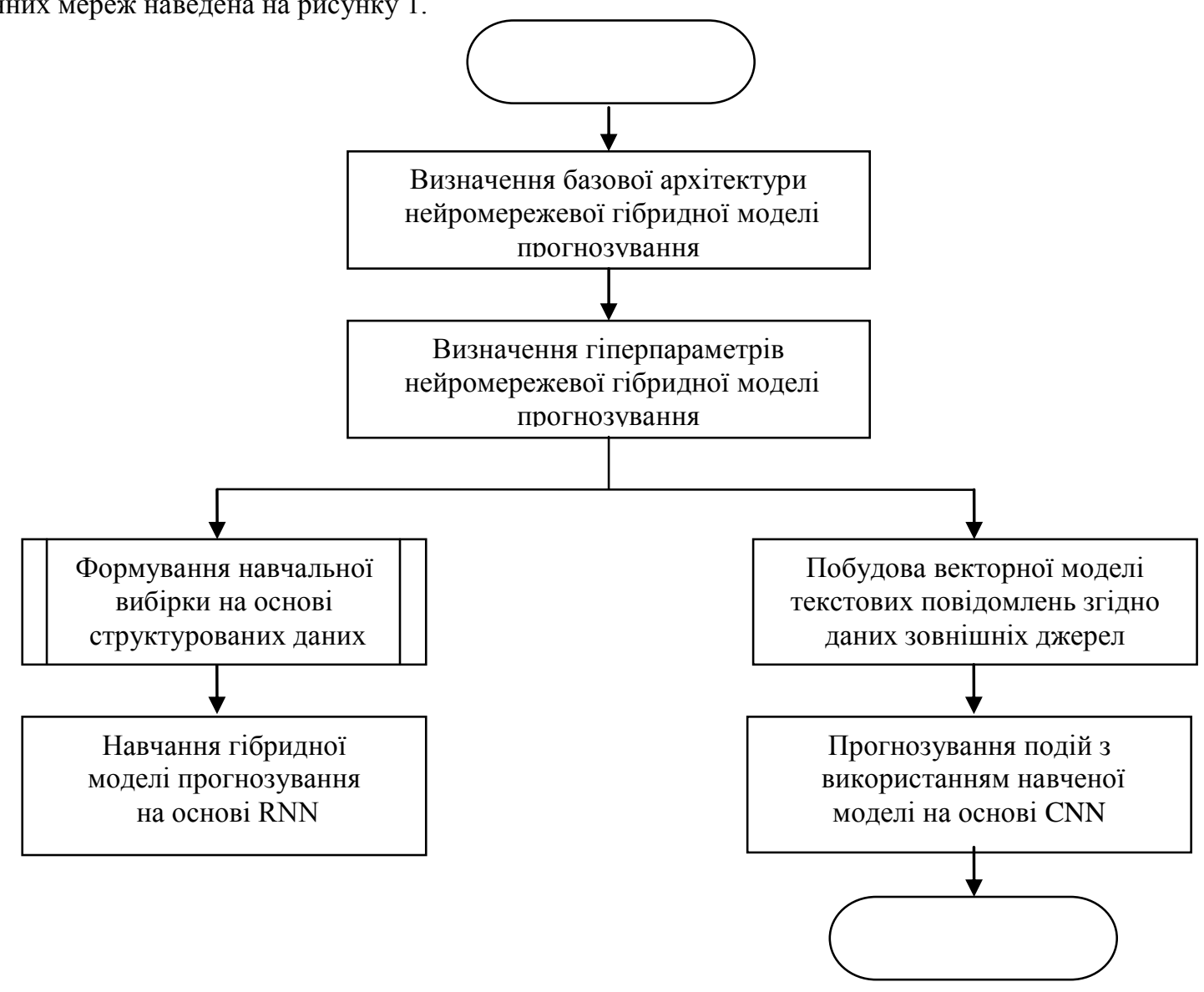

Рис.1- Загальна структура методу прогнозування несприятливих авіаційних подій під час польоту на основі гібридних нейронних мереж

Архітектура моделі прогнозування несприятливих авіаційних подій в польоті базується на гібридній моделі на основі згорткової нейронної мережі (Convolutional neural network $\square$ CNN) [5], яка використовується при функціонуванні гібридної нейромережевої моделі прогнозування несприятливих авіаційних подій в польоті та LSTM [6] і використовується при навчанні гібридної нейромережевої моделі прогнозування;

2) процедури визначення гіперпараметрів гібридної нейромережевої моделі для прогнозування несприятливих авіаційних подій в польоті з використанням CNN і LSTM;

3) процедури навчання гібридної нейромережевої моделі та формування значень ваг шару Embedding [7] для прогнозування несприятливих авіаційних подій в польоті 3 навчальної вибіркою, отриманою методом формування навчальної вибірки. В якості базової топології нейронної мережі використовується топологія LSTM;

4) процедури побудови векторної моделі текстових повідомлень від зовнішніх джерел в процесі прогнозування несприятливих авіаційних подій в польоті. Дана процедура аналогічна відповідній процедурі побудови векторної моделі текстових повідомлень по навчальним прикладам, яка виконується при формуванні навчальної вибірки;

5) процедури прогнозування несприятливих авіаційних подій в польоті на основі функціонування навченої гібридної нейромережевої моделі з використанням CNN та навченого шару LSTM.

Розглянемо більш детально деякі 3 наведених вище процедур.

В якості базових гіперпараметрів гібридної нейромережевої моделі прогнозування несприятливих авіаційних подій в польоті розглядаються базові елементи нейронних мереж CNN i LSTM.

1) базові шари:

- згорткові шари (Convolution Layers, CONVшари). CONV-шар обчислює значення виходів нейронів, які 3'єднані 3 рецептивними полями (фільтрами, що навчаються ) вхідного шару, для опису ознак зображення у вигляді багатовимірного масиву карт ознак; 
- шари об’єднання (Pooling Layers, POOLшари). POOL-шар забезпечує зниження просторового розміру зображення (карт ознак) для зменшення кількості параметрів та обчислювальної складності мережі;

- шари активації: безпосередньо в роботі використовується шар випрямлення (Rectified Linear Unit, шари ReLU). Шар ReLU це лінійний блок випрямлення, що розглядається як функція активації нейронів CONV-шару;

- шар Embedding - забезпечує безпосереднє кодування слів, де кожному слову 3 розглянутої предметної області присвоюється вектор заданої розмірності. Кодування слів за допомогою векторів помірного розміру шаром Embedding знімає проблему перенавчання;

2) допоміжні шари:

- шар конкатенації або зв'язування (Concatenation, Concat-шар). Concat-шар забезпечує об'єднання різних вихідних багатовимірних масивів карт ознак, отриманих в результаті функціонування шарів нейронної мережі, в один;

- шари даних (Date Layers) - шари, через які здійснюється безпосереднє введення первинних даних про зображення.

Представимо розмірність вхідних даних $X$ довільного $i$-го шару у вигляді кортежу $H^{i n}, W^{i n}, D^{\text {in }}$ де величина $H^{\text {in }}$ визначає висоту вхідної матриці (кількість слів у повідомленні), $W^{\text {in }}$ визначає ширину вхідної матриці (довжину вектора для кодування вхідного слова) та $D^{i n}$ глибину вхідної матриці. Для вхідних даних шару Embedding глибина характеризує кількість вхідних повідомлень, що оброблюються. Для даних, що передаються між прихованими шарами підмережі, глибина характеризує кількість карт ознак. Розмірність вихідних даних $Y$ для $\boldsymbol{i}$-го шару формально представимо у вигляді кортежу $H^{\text {out }}, W^{\text {out }}, D^{\text {out }}$. Тоді розмірність рецептивного поля $F \quad i$-го шару як багатовимірного фільтра в загальному випадку представимо у вигляді кортежу $H^{f}, W^{f}, D^{\text {in }}, D^{\text {out }}$. При цьому, будемо вважати, що $W^{f}=H^{f}$.

Формально структуру CONV-шару, що $\epsilon$ основною обчислювальної одиницею мережі, представимо у вигляді наступного кортежу:

$$
C O N V=X, F, Y, B, P_{h}^{-}, P_{h}^{+}, P_{w}^{-}, P_{w}^{+}, S_{h}, S_{w}, n^{\text {par }} \text { (1) }
$$

де $X$ - багатовимірний масив вхідних даних, що представляє вхідне текстове повідомлення або множину вхідних карт ознак для довільного шару $X \subset \mathrm{R}^{H^{i n} \times W^{i n} \times D^{i n}} ;$

$F-$ багатомірний фільтр, що представляє собою множину рецептивних полів, $F \subset \mathrm{R}^{H^{f} \times W^{f} \times D^{\text {in }} \times D^{\text {out }}} ;$

$Y$ - багатомірний масив вихідних даних, що представляють собою множину вихідних карт ознак, $Y \subset \mathrm{R}^{H^{\text {out }} \times W^{\text {out }} \times D^{\text {out }}}$;

$B$ - множина значень «нейроних зміщень»;

$P_{h}^{-}, P_{h}^{+}, P_{w}^{-}, P_{w}^{+} \quad$ - вектор нулів вирівнювання кодованого вхідного текстового повідомлення по нижньому, верхньому, лівому та правому краю фильтра відповідно;

$S_{h}, S_{w} \quad-\quad$ вектор кроку зміщення рецептивного поля по висоті та ширині матриці слів відповідно;

$n^{\text {par }}$ - кількість навчаємих параметрів CONVшару.

Кількість навчаємих параметрів CONV-шару визначається відповідно до виразу:

$$
n^{\text {par }}=H^{f} D^{f} D^{\text {in }} D^{\text {out }}+|B|
$$

При цьому характеристики вихідних даних CONV-шару, формально представлених у вигляді кортежу $H^{\text {out }}, W^{\text {out }}, D^{\text {out }}$ визначаються згідно виразів:

$$
\begin{aligned}
& W^{\text {out }}=\frac{W^{\text {in }}-W^{f}+P_{w}^{+}+P_{w}^{-}}{S_{w}}+1, W^{\text {in }}+P_{w}^{+}+P_{w}^{-} \geq W^{f} ; \\
& H^{\text {out }}=\frac{H^{\text {in }}-H^{f}+P_{h}^{+}+P_{h}^{-}}{S_{h}}+1, H^{\text {in }}+P_{h}^{+}+P_{h}^{-} \geq H^{f}
\end{aligned}
$$

де $n^{f}-$ кількість рецептивних полів CONVшару.

Згортковий шар можливо представити у вигляді функції:

$$
\begin{aligned}
& Y_{H^{\text {out }} W^{\text {out }} D^{\text {out }}}=f_{C O N V} X_{H^{i n} W^{i n} D^{\text {in }}} \\
& \text { де } X_{H^{i n} W^{i n} D^{i n}}-\text { коваріантний тензор }
\end{aligned}
$$
третього рангу, який описує вхідні дані CONVшару;

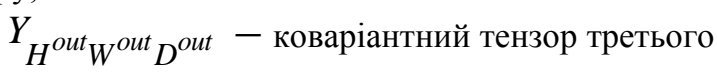
рангу, який описує вихідні дані CONV-шару.

3 урахуванням формального представлення CONV-шару згідно (1), результат визначення

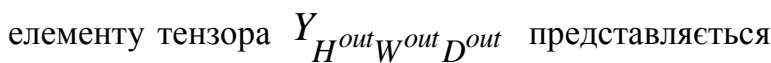
як:

$$
\begin{aligned}
& y_{i^{\text {out }} j^{\text {out }} k^{\text {out }}}=b_{k^{\text {out }}+} \\
& +\sum_{i^{i n}=0}^{H^{f}-1} \sum_{j^{i n}=0}^{W^{f}-1} \sum_{k^{\text {in }}=1}^{D^{\text {in }}} f_{k^{\text {out }}}^{i^{f} j^{f^{i n}}} * x_{i^{\text {in }}+i^{\text {out }}} j^{\text {in }+i^{\text {out }}} k^{\text {in }} \\
& \text { де } y_{i} \text { out } j^{\text {out }} k^{\text {out }}-\text { елемент тензору }
\end{aligned}
$$

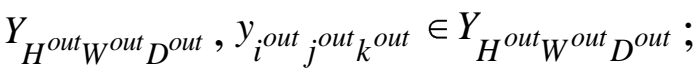

$$
\begin{aligned}
& b_{k^{\text {out }}} \text { - елемент множини } B, b_{k^{\text {out }}} \in B \text {; } \\
& f_{k^{\text {out }}}^{i^{f} j^{f} k^{i n}}-\text { елемент комбінованого тензору }
\end{aligned}
$$
четвертого рангу $F_{D^{\text {out }}}^{H^{f} W^{f}} D^{\text {in }}$, який описує рецептивні поля CONV-шару, $f_{k^{\text {out }}}^{i^{f} j^{f} k^{\text {in }}} \in F_{D^{\text {out }}}^{H^{f} W^{f} D^{\text {in }}} ;$

$x_{i}^{\text {in }}+i^{\text {out }} j^{\text {in }}+i^{\text {out }} k^{\text {in }}-$ елемент тензору $X_{H^{i n} W^{i n} D^{i n}}, x i^{\text {in }}+i^{\text {out }} \quad j^{\text {in }}+i^{\text {out }} k^{\text {in }} \in X_{H^{i n} W^{i n}} D^{\text {in }} ;$ * - операція згортки спряжених тензорів. 
Формально структуру шару активації представимо наступним кортежем:

$$
A C T=X, Y, t^{\mathrm{ACT}}
$$

де $X-$ багатомірний масив вхідних даних, що являє собою множину вхідних карт ознак, $X \subset \mathrm{R}^{H^{i n} \times W^{i n} \times D^{i n}} ;$

$Y$ - багатомірний масив вихідних даних, що являє собою множину вихідних карт ознак, $Y \subset \mathrm{R}^{H^{\text {out }} \times W^{\text {out }} \times D^{\text {out }}}$;

$t^{\mathrm{ACT}}-$ множина типів функцій активації.

В даній роботі буде використовуватися функція активації ReLU [8]:

$$
\begin{aligned}
& y_{i^{\text {out }} j^{\text {out }} k^{\text {out }}}=\mathrm{S} x_{i^{\text {in }} j^{\text {in }} k^{\text {in }}}=\max 0, x_{i^{\text {in }}} j_{j}^{\text {in }} k^{\text {in }} \\
& \text { де }
\end{aligned}
$$

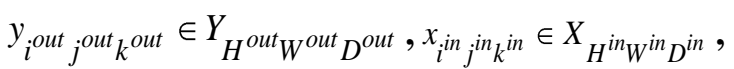

$$
\begin{aligned}
& H^{\text {out }}=H^{\text {in }}, W^{\text {out }}=W^{\text {in }}, D^{\text {out }}=D^{\text {in }} .
\end{aligned}
$$

Шар активації, який реалізує функцію ReLU, представимо в вигляді:

$$
Y_{H^{\text {out }} W^{\text {out }} D^{\text {out }}}=f_{R e L U} X_{H^{\text {in }} W^{\text {in }} D^{\text {in }}}
$$

Формально структуру POOL-шару можна представити у вигляді наступного кортежу:

$$
\text { POOL }=X, Y, H^{\text {Pool }}, W^{\text {Pool }}, S_{h}, S_{w}, t^{\text {Pool }}
$$

де $X$ - багатомірний масив вхідних даних, що являє собою множину вхідних карт ознак, $X \subset \mathrm{R}^{H^{i n} \times W^{i n} \times D^{i n}} ;$

$Y$ - багатомірний масив вихідних даних, що являє собою множину вихідних карт ознак, $Y \subset \mathrm{R}^{H^{\text {out }} \times W^{\text {out }} \times D^{\text {out }}} ;$

$$
H^{\text {Pool }}, W^{\text {Pool }}-\text { просторові розміри вікна }
$$

об'єднання POOL-шару;

$S_{h}, S_{w} \quad$ - крок зсуву рецептивного поля;

$t^{\text {Pool }}-$ множина типів операцій об'єднання,

$$
t^{\text {Pool }}=\text { "max", "avg”, "sum” . }
$$

В даному дослідженні безпосередньо використовуємо два типи операцій “тах" та "avg".

Характеристики вихідних даних POOL-шару визначаються згідно наступних виразів:

$$
\begin{aligned}
& W^{\text {out }}=\frac{W^{\text {in }}-W^{\text {Pool }}}{S_{w}}+1 \\
& H^{\text {out }}=\frac{H^{\text {in }}-H^{\text {Pool }}}{S_{h}}+1 \\
& D^{\text {out }}=D^{\text {in }}
\end{aligned}
$$

Представимо шар об'єднання у вигляді наступних функцій:
- для операції “таx” :

$$
\begin{aligned}
& Y_{H^{\text {out }} W^{\text {out }} D^{\text {out }}}=f_{\text {MaxPOOL }} X_{H^{\text {in }} W^{\text {in }} D^{\text {in }}} \\
& \text { - для операції “avg”: }
\end{aligned}
$$$$
Y_{H^{\text {out }} W^{\text {out }} D^{\text {out }}}=f_{\text {AvgPOOL }} X_{H^{\text {in }} W^{\text {in }} D^{\text {in }}}
$$

$H^{\text {out }} W^{\text {out }} D^{\text {out }}=f_{\text {AvgPOOL }} H^{\text {in }} W^{\text {in }} D^{\text {in }}$

3 урахуванням формального уявлення POOLшару, відповідно до виразу (10), результат визначення елементу тензора $Y_{H^{\text {out }}} W^{\text {out }} D^{\text {out }}$ представляється для операцій “таx" та " $a v g$ ” як:

$$
\begin{aligned}
& y_{i^{\text {out }} j^{\text {out }} k^{\text {out }}}= \\
& =\max _{1 \leq i} \operatorname{mool}_{\leq H^{\text {pool }}, 1 \leq j} x_{i^{\text {pool }} \leq W^{\text {pool }}-1} j^{\text {in }}+i^{\text {out }}-1 k^{\text {in }} \\
& y_{i^{\text {out }} j^{\text {out }} k^{\text {out }}}=\frac{1}{H^{\text {pool }} W^{\text {pool }}} \text {. } \\
& \sum_{1 \leq i^{\text {pool }} \leq H^{\text {pool }}, 1 \leq j^{\text {pool }} \leq W^{\text {pool }}} x_{i^{\text {in }}+i^{\text {out }}-1} j^{\text {in }+i^{\text {out }}-1 k^{\text {in }}} \\
& \text { де }
\end{aligned}
$$

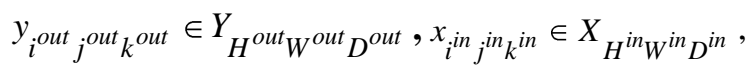

$$
\begin{aligned}
& D^{\text {out }}=D^{\text {in }} \text {. }
\end{aligned}
$$

Процедура навчання гібридної нейромережевої моделі для прогнозування несприятливих авіаційних подій під час польоту повністю визначається алгоритмом навчання нейронної мережі на основі модуля LSTM. В якості навчальної вибірки використовуються структуровані дані у вигляді звітів про результати розслідування несприятливих авіаційних подій під час польоту (від 100 до 5000 навчальних прикладів). Надалі, на основі технології Transfer Lesrning [8], на вхід нейронної мережі для прогнозування несприятливих авіаційних подій під час польоту передається налаштований в процесі навчання шар Embedding. Нейронна мережа донавчається 3 використанням навчальної вибірки у вигляді неструктурованих даних про поточну обстановку в польоті (від 100 до 500 навчальних прикладів). Схема реалізації даної процедури представлена на рисунку 2.

Навчання RNN на основі модуля LSTM аналогічне навчанню класичної нейронної мережі [7]. При цьому в якості базового алгоритму навчання використовується алгоритм зворотного поширення помилки (backpropagation).

Безпосередньо порядок функціонування та навчання RNN на основі модулів LSTM полягає в реалізації наступних етапів:

- шар векторного уявлення слів Embedding перетворює кожен вхід (тензор з k слів) в тензор $\mathrm{k}$ $\mathrm{N}$-мірних векторних уявлень слів (N - розмір уявлення);

- кожному слову, характерному для повідомлень про результати розслідування авіаційних подій, ставиться у відповідність вектор ваг, який необхідно вивчити під час процесу навчання мережі;

створюється тензор, який представляє собою повідомлення про результати розслідування авіаційної події;

- 3 використанням шарів RNN на основі блоків модулів LSTM (с використанням шару Dropout) виконується безпосередня настройка ваг 
LSTM під час навчання 3 використанням ВРТT. RNN шар розгортається динамічно, приймаючи на вхід k-векторних уявлень і видає М-мірні вектора, де М - в загальному випадку кількість LSTM-модулів в блоці;

- шар Softmax реалізує вихід RNN шару 3 усередненням через $\mathrm{k}$ тимчасових кроків. Формується тензор розмірності $\mathrm{M}$, який використовується для обчислення ймовірностей для задачі прогнозування несприятливих авіаційних подій під час польоту.

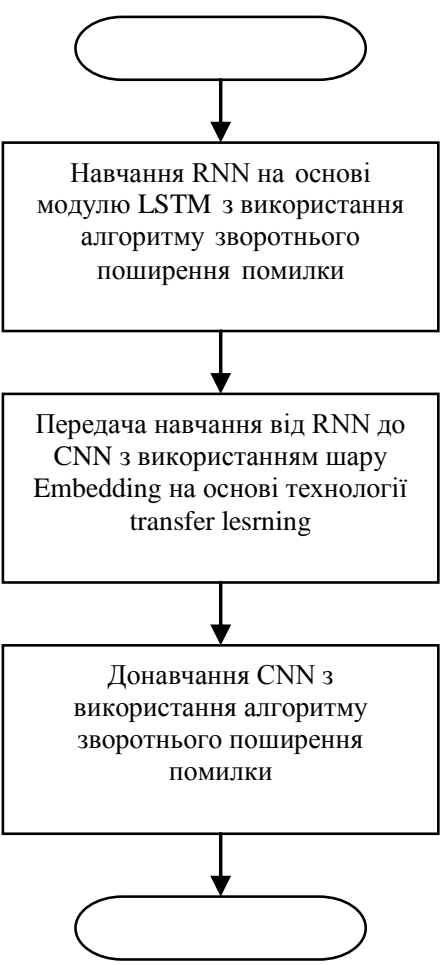

Рис.2 $\square$ Структурна схема реалізації процедури навчання гібридної нейромережевої моделі для прогнозування несприятливих авіаційних подій під час польоту

Процедура прогнозування несприятливих авіаційних подій під час польоту з використанням навченої гібридної нейромережевої моделі реалізується за допомогою виконання сукупності таких операцій (рис.3):

1) подання вхідних слів в шарі даних у вигляді

\section{Лimepamypa}

1. Справка. Состояние безопасности полетов в гражданской авиации государств-участников соглашения о гражданской авиации и об использовании воздушного пространства в первом полугодии 2018 г. URL: https://makiac.org/upload/iblock/5b0/bp-18-1.pdf. 2. Statistical Summary of Commercial Jet Airplane Accidents. Worldwide Operations 19592008, Boeing Commercial Airplanes, Seattle, Washington 981242207, USA. 3. Шаров В.Д. Применение байесовского подхода для уточнения вероятностей событий в автоматизированной системе прогнозирования и предотвращения авиационных происшествий / В. Д. Шаров // Управление большими системами. -2013. №43. - С.240 - 253. тривимірного масиву (тензору) розмірністю, векторних уявлень слів (векторної моделі текстових повідомлень) за даними від зовнішніх джерел;

2) реалізація прямого проходу CONV-шарів i прошарків ReLU відповідно до виразів (6) та (8). Кількість CONV-шарів i прошарків ReLU визначається архітектурою нейронної мережі;

3) реалізація прямого проходу MaxPOOL-шару у відповідності до виразу (16) і архітектурою нейронної мережі прогнозування несприятливих авіаційних подій в польоті;

4) реалізація прямого проходу додаткових CONV-шарів без шарів ReLU згідно виразу (6);

5) (8) реалізація прямого проходу AvgPOOLшару у відповідності з виразом (17) і архітектурою нейронної мережі;

9) карти ознак, розраховані на виході AvgPOOL-шару, об'єднуються в один загальний вектор ознак. Він подається на вхід прихованого повнозв'язну шару, а потім надходить на вихідний шар Softmax нейронної мережі, де i розраховуються підсумкові мітки класів для прогнозування несприятливих авіаційних подій в польоті.

\section{Висновки і перспективи подальших досліджень}

В роботі представлено структуру методу прогнозування несприятливих авіаційних подій під час польоту на основі згорткових $(\mathrm{CNN})$ та рекурентних нейронних мереж (RNN) на базі модулів LSTM.

RNN в контексті вирішення задачі прогнозування несприятливих авіаційних подій під час польоту використовуються для початкового налаштування шару Embedding на структурованих навчальних даних в процесі навчання гібридної нейросетевой моделі.

CNN використовуються в процесі безпосереднього функціонування гібридної нейромережевої моделі прогнозування несприятливих авіаційних подій в польоті.

4. Макаров В.П. Метод прогнозирования и предупреждения авиационных происшествий на основе анализа “дерева факторов опасности": дисер. канд. техн. наук / В.П. Макаров. - М., 2013. - 137c. 5. Y. Kim. Convolutional neural networks for sentence classification. arXiv:1408.5882 [cs.CL], 2014. 6. C. Olah. Neural networks, recurrent neural networks, convolutional neural networks. http://colah.github.io/. 7. dos Santos C.N., Gatti M. Deep Convolutional Neural Networks for Sentiment Analysis of Short Texts // COLING, 2014. P. 69 - 70. 8. S.Hochreiter, J.Schmidhuber. Long short-term memory // Neural computation 9, 1997. Issue 8. P. 1735

1780. 
МЕТОД ПРОГНОЗИРОВАНИЯ НЕБЛАГОПРИЯТНЫХ АВИАЦИОННЫХ ПРОИСШЕСТВИЙ

В ПОЛЕТЕ НА ОСНОВЕ ГИБРИДНЫХ НЕЙРОННЫХ СЕТЕЙ

\author{
Евгений Александрович Гришманов ${ }^{1}$ \\ Ирина Викторовна Захарченко (кандидат технических наук) ${ }^{2}$ \\ Ирина Викторовна Новикова ${ }^{3}$

\footnotetext{
${ }^{1}$ Летная академия Национального авиационного университета, Кропивницкий, Украина

${ }^{1}$ Харьковский национальный университет Воздушньх Сил имени Ивана Кожедуба, Харьков, Украина

${ }^{3}$ Национальный университет оборони Украины имени Ивана Черняховского, Киев, Украина
}

В работе представлена структура метода прогнозирования неблагоприятных авиационных происшествий в полете на основе сверточных нейронных сетей (CNN) и рекуррентных нейронных сетей $(R N N)$ на базе модулей LSTM. Непосредственно под прогнозированием в работе имеется в виду решения задачи анализа текстовых сообщений, представленных в виде структурированного и неструктурированного текста, которые формируются на основе данных, полученных от различных источников информачии в прочессе управления воздушным движением. Детально рассмотрень процедурь определения гиперпараметров и обучения гибридной нейросетевой модели для прогнозирования неблагоприятных авиаџионных событий в полете с использованием сетей CNN u модулей LSTM.

Ключевые слова: безопасность полетов, прогнозирования, сверточная нейронная сеть, рекуррентная нейронная сеть, модуль LSTM, функиия активации, тензор.

\title{
METOD OF FORECASTING OF UNFAVORABLE AIRCRAFT ACCIDENTS IN THE FLIGHT BASED ON HYBRID NEURAL NETWORKS
}

\author{
Evhenii Gryshmanov ${ }^{1}$ \\ Iryna Zakharchenko (Candidate of technical sciences) ${ }^{2}$ \\ Iryna Novikova ${ }^{3}$ \\ ${ }^{1}$ Flight Academy of National Aviation University, Kropivnitsky, Ukraine \\ ${ }^{3}$ National Defence University of Ukraine named after Ivan Cherniakhovsky, Kyiv, Ukraine
}

${ }^{2}$ Kharkov National Air Force University named after Ivan Kozhedub, Kharkov, Ukraine

The paper describes the structure of a method for forecasting of unfavorable aircraft accidents in the flight that uses convolutional neural networks (CNN) and recurrent neural networks (RNN) based on LSTM modules. In this work, forecasting means solving the problem of analyzing text messages. They are presented as a structured and unstructured text and are formed based on data obtained from various sources of information in the process of air traffic control. The procedures for determining hyperactive parameters and training a hybrid neural network model for forecasting of unfavorable aircraft accidents in the flight using CNN networks and LSTM modules are considered in detail.

Keywords: flight safety, forecasting, convolutional neural network, recurrent neural network, LSTM module, activation function, tensor.

\section{References}

1. Fact sheet. Status of civil aviation safety of the States Parties to the Agreement on Civil Aviation and the Use of Air in the first half of 2018. URL: https://mak-iac.org/upload/iblock/5b0/bp-18-1.pdf. 2. Statistical Summary of Commercial Jet Airplane Accidents. Worldwide Operations 19592008, Boeing Commercial Airplanes, Seattle, Washington 981242207, USA. 3. V.D.Sharov. Application of the Bayesian approach for specifying the probabilities of events in the automated system of forecasting and prevention of aviation accidents / V.D.Sharov // Management of large systems. - 2013. №43. - C.240 - 253. 4. V.P.Makarov. Method of forecasting and

prevention of aviation accidents on the basis of the "Factors hazard tree" analysis: Dissertation Candidate of Technical Sciences / V.P.Makarov. - M., 2013. P.137. 5. Y. Kim. Convolutional neural networks for sentence classification. arXiv:1408.5882 [cs.CL], 2014. 6. C. Olah. Neural networks, recurrent neural networks, convolutional neural networks. http://colah.github.io/. 7. Dos Santos C.N., Gatti M. Deep Convolutional Neural Networks for Sentiment Analysis of Short Texts // COLING, 2014. P. $69-70$. 8. S.Hochreiter, J.Schmidhuber. Long short-term memory // Neural computation 9, 1997. Issue 8. P. $1735-1780$. 